\title{
Boron, nitrogen co-doped graphene: a superior electrocatalyst support and enhancing mechanism
}

\section{for methanol electrooxidation}

Yongrong Sun a,b, Chunyu Du a,b*, Guokang Han ${ }^{\mathrm{b}}$, Yunteng Qu ${ }^{\mathrm{b}}$, Lei Du ${ }^{\mathrm{b}}$, Yajing Wang ${ }^{\mathrm{b}}$, Guangyu Chen ${ }^{\mathrm{b}}$, Yunzhi

$$
\text { Gao a,b, Geping Yin a,b }
$$

${ }^{a}$ Key Laboratory of Materials for New Energy Conversion and Storage, Ministry of Industry and Information Technology, Harbin Institute of Technology, Harbin 150001, China

${ }^{b}$ Institute of Advanced Chemical Power Sources, School of Chemical Engineering and Technology, Harbin Institute of Technology, 150001, China.

${ }^{*}$ Corresponding author

Tel: +86-451-86403961; Fax: +86-451-86418616

E-mail address: cydu@ hit.edu.cn (C. Du)

(C) 2016. This manuscript version is made available under the Elsevier user license http://www.elsevier.com/open-access/userlicense/1.0/ 
Abstract: Boron, nitrogen co-doped graphene (BNG) is facilely synthesized by the two-step thermal annealing of graphene in the presence of melamine and boric acid, which is served as a novel support to enhance the catalytic properties of noble metal catalysts for the methanol oxidation reaction (MOR). It is revealed that the BNG support has more defect sites due to the co-doping of boron and nitrogen, so that uniformly dispersed Pt nanoparticles with average size of $2.3 \mathrm{~nm}$ are anchored on the surface of BNG support. The BNG supported Pt (Pt/BNG) catalyst exhibits excellent activity and improved stability towards the MOR, which is mainly attributed to the synergetic effects of boron and nitrogen co-doping into graphene support. It is revealed that nitrogen and boron co-doping produces more oxygen-containing species, which accelerates the methanol oxidation by the so-called bifunctional mechanism. Moreover, the boron doping weakens the adsorption energy of poisoning intermediates on Pt surface by lowering the d-band center of $\mathrm{Pt}$, facilitating the oxidative removal of poisoning intermediates and methanol oxidation. The boron and nitrogen co-doping of graphene opens up a new strategy for the catalyst performance optimization.

Keywords: Boron and nitrogen co-doped graphene, catalyst support, electrocatalysis, carbon monoxide tolerance, methanol oxidation 


\section{Introduction}

Metal nanocatalysts dispersed on supports play a pivotal role in the fields of energy storage/conversion, environmental protection and sustainable production of chemicals [1]. It has been demonstrated that the properties of metal catalysts depend highly on their interaction with supports [2]. Graphene, as a unique class of two-dimensional single atomic layer of $\mathrm{sp}^{2}$ hybridized carbon atoms, has attracted tremendous attention for potential applications in catalysis [3], because of its huge surface area, unique graphitized basal plane structure and high electronic conductivity. In particular for electrocatalytic applications, as a highly stable and conductive platform to anchor catalyst nanoparticles, graphene opens up new possibilities for designing the next generation electrocatalyst supports [4]. Unfortunately, pure graphene is difficult to uniformly anchor catalyst nanoparticles due to its perfect graphitization, low defect level and smooth surface. More importantly, the interaction between metal catalyst and graphene is not strong, which is not good for enhancing the catalytic properties of metal catalysts [5-7].

Heteroatom doping is an effective approach to producing a large number of defect sites in the basal planes and edges of graphene sheets, which can serve as loading sites for anchoring catalyst nanoparticles [8]. Moreover, the interaction of graphene with metal catalyst can be tailored by the heteroatom doping [2]. Doping with heteroatoms of nitrogen [9-11], boron [12], sulfur [13], and phosphorus [14] have been proved to effectively modify the physical, chemical, and electronic properities of graphene materials. Among numerous dopants, nitrogen is commonly considered to be an excellent choice for the chemical doping of graphene materials because it has comparable atomic size and contains five valence electrons available to form strong valence bonds with carbon atoms [15]. The formed C-N bonds promote the dispersion of metal nanoparticles [16-18], which is mainly attributed to the pyridinic type nitrogen species that is a good ligand and interacts strongly with metal catalysts 
[19-20].

Nitrogen-doped graphene supported Pt nanoparticles (Pt/NG) have already been employed as the electrocatalyst towards the methanol oxidation reaction (MOR) [2,5,21], which is regarded as one of the most important oxidation reactions of small molecules, especially for direct type fuel cells. It is reported that the Pt/NG catalyst exhibits high MOR catalytic activity and stability [22], which is ascribed to, on the one hand, the well dispersed Pt nanoparticles on NG support, leading to high electrochemical active surface area, and on the other hand, the increased defect level and thus oxygen-containing species on NG support, facilitating the removal of poisoning intermadiates by the so-called bifunctional mechanism [19]. However, the MOR kinetics of Pt/NG catalyst is still slow and cannot meet the requirement for practical applications because of the scarce resources and the soaring price of Pt. As we know, the rate-determining step of MOR is the slow adsorption and dehydrogenation of methanol at low potentials or the poisoning of reaction intermediates (commonly CO) at high potentials. Methanol is a polar molecule with negative charge accumulated on oxygen atoms and tends to adsorb on metal surface via lone-pair electrons of oxygen atoms [23]. However, the doping of nitrogen with high electronegativity into graphene decreases the electron density of its supported Pt, increasing the adsorption energy and reducing adsorption rate of methanol on Pt surface at low potentials [24]. Meanwhile, nitrogen doped graphene increases the d-band center of Pt, which enhances the adsorption of $\mathrm{CO}$ intermediate on $\mathrm{Pt}$ surface according to the d-band center theory from Nørskov [25], slowing down the oxidation removal of methanol at high potentials. Thus, Pt/NG catalyst does not exhibit the desirable MOR kinetics, although its MOR activity is higher than that of $\mathrm{Pt} / \mathrm{G}$ catalyst because the defect sites and oxygen-containing species on $\mathrm{N}$-doped graphene facilitate the removal of poisoning intermediates by the bifunctional mechanism.

Herein, in order to further enhance the MOR activity, we demonstrate the facile synthesis of boron, 
nitrogen co-doped graphene (BNG) by the two-step thermal annealing of graphene in the presence of melamine and boric acid. This BNG material is employed as the electrocatalyst support, onto which Pt nanoparticles are deposited by a microwave-assisted polyol reduction approach. On the one hand, nitrogen doping produces a large number of anchoring sites on graphene for uniformly dispersing Pt nanoparticles, and enhances their MOR activity by the bifunctional mechanism. On the other hand, the doping of boron atoms with low electronegativity can increase the electron density of Pt and lower the d-band center of $\mathrm{Pt}$, which is beneficial to decreasing the bond energy of $\mathrm{C}-\mathrm{H}$ bond of methanol molecules[26] and the adsorption energy of CO intermediate [27], promoting methanol dehydrogenation and $\mathrm{CO}$ oxidation. Our approach integrates the benefits of nitrogen doping and boron doping, which synergically contribute to the activity and stability of supported Pt catalyst. Therefore, the BNG supported Pt catalyst, Pt/BNG, shows remarkably enhanced electrocatalytic properties than the Pt/NG catalyst. Although the boron, nitrogen co-doped graphene has been employed as a main catalyst for the oxygen reduction reaction [28,29], this is the first report of its usage as the support of Pt catalyst for the MOR.

\section{Experimental}

\subsection{Preparation of graphene oxide}

Graphene oxide (GO) was synthesized by the Hummers method [30]. Briefly, 5 g of graphite powder was mixed with $180 \mathrm{~mL}$ of concentrated $\mathrm{H}_{2} \mathrm{SO}_{4}$, into which $60 \mathrm{~mL}$ of concentrated $\mathrm{HNO}_{3}$ was added and stirred for $1 \mathrm{~h}$. Under vigorous stirring, $25 \mathrm{~g}$ of $\mathrm{KMnO}_{4}$ was slowly added to the suspension. After the mixture was stirred at room temperature for $120 \mathrm{~h}$, the resultant slurry was diluted with 1000 $\mathrm{mL}$ of deionized water to terminate the reaction and the mixture turned into bright yellow by adding 30 wt. $\% \mathrm{H}_{2} \mathrm{O}_{2}$ under stirring for $2 \mathrm{~h}$. The product was filtered, washed with a mixture of $35 \mathrm{~mL}$ of $\mathrm{HCl}, 15$ 
$\mathrm{mL}$ of $\mathrm{H}_{2} \mathrm{O}_{2}$ and $500 \mathrm{~mL}$ of deionized water and subsequently excess water until $\mathrm{pH}$ value was neutral. Finally, the sample was transferred into a Petri dish with diameter of $6 \mathrm{~cm}$, and the product was obtained by freeze-drying at $-50{ }^{\circ} \mathrm{C}$ under vacuum for $12 \mathrm{~h}$.

\subsection{Synthesis of $B, N$ co-doped graphene}

$\mathrm{B}, \mathrm{N}$ co-doped graphene (BNG) was prepared by a simple thermal annealing process. First, GO was dispersed into deionized water and ultrasonically treated for $6 \mathrm{~h}$. Then, melamine was added into the GO suspension and ultrasonically treated for another $6 \mathrm{~h}$. After the mixture was freeze-dried, the obtained solid mixture was put into a quartz boat and annealed under $\mathrm{H}_{2} / \mathrm{Ar}\left(\mathrm{H}_{2}\right.$ 5\%/Ar 95\%) atmosphere at 1000 ${ }^{\circ} \mathrm{C}$ for $2 \mathrm{~h}$ to form the nitrogen doped graphene (NG). Subsequently, the NG sample was sonicated in deionized water for $6 \mathrm{~h}$, and boric acid was added and sonicated for another $6 \mathrm{~h}$. After freeze-drying, the mixture was heat treated at $1000{ }^{\circ} \mathrm{C}$ for $2 \mathrm{~h}$ by flowing $\mathrm{H}_{2} / \mathrm{Ar}$ gases. The product was dispersed into hot water to remove the impurity, and the BNG product was finally obtained.

\subsection{Synthesis of BNG supported Pt (Pt/BNG) catalyst}

The BNG supported Pt (Pt/BNG) catalyst with 40 wt.\% Pt loading was prepared by a microwave-assisted polyol reduction process in ethylene glycol solution. Briefly, $20 \mathrm{mg}$ of BNG support was added into the mixture of $10 \mathrm{~mL}$ of isopropanol and $40 \mathrm{~mL}$ of ethylene glycol, and ultrasonicated for $30 \mathrm{~min}$ to form a uniform suspension. This suspension was stirred for $6 \mathrm{~h}$ at room temperature. After that, $0.6 \mathrm{~mL}$ of $\mathrm{H}_{2} \mathrm{PtCl}_{6}$ solution $(0.115 \mathrm{M})$ was dropwise added to the mixture and its $\mathrm{pH}$ value was adjusted to 11 using $1.0 \mathrm{M} \mathrm{NaOH}$ solution. The mixture was then subject to microwave heating (2450 $\mathrm{MHz}, 800 \mathrm{~W}$ ) for $60 \mathrm{~s}$. After cooling down to room temperature, $\mathrm{pH}$ value of the mixture was adjusted to 2 using $1.0 \mathrm{M} \mathrm{HNO}_{3}$ and magnetically stirred overnight. Finally, the product was separated by 
dialysis, filtration, washing with a large amount of hot water and drying in vacuum at $80{ }^{\circ} \mathrm{C}$ for $12 \mathrm{~h}$. The NG supported Pt (Pt/NG) catalyst with 40 wt.\% of Pt loading was also prepared by the same procedure.

\subsection{Physical characterization}

Raman spectra were collected on a Raman spectrometer (HR800, JY Company) with $457.9 \mathrm{~nm}$ laser. X-ray diffraction (XRD) patterns were recorded on a Bruker D8 diffractometer using $\mathrm{Cu}-\mathrm{K \alpha}(\lambda=$ $1.5406 \AA$ A) radiation. The morphology and structure of NG, BNG, Pt/NG and Pt/BNG samples were characterized by transmission electron microscopy (TEM) using an H-7650 (Hitachi, Japan) instrument operating at $200 \mathrm{kV}$. X-ray photoelectron spectroscopy (XPS) measurements were performed by a Physical Electronics PHI model 5700 instrument using Al Ka radiation (1486.6 eV). The binding energy for all samples was calibrated by the C 1s binding energy of graphite carbon at $284.6 \mathrm{eV}$. Surface area and pore size distribution of samples were determined by recording nitrogen adsorption-desorption isotherms using a 3H-2000PS1 gas adsorption analyzer (Bei Shi De, China). Pt content in all the samples was determined by inductively coupled plasma mass spectrometry (ICP-MS) using Agilent 7700 instrument.

\subsection{Electrochemical measurements}

The electrochemical tests were carried out using CHI 604D workstation in a standard three-electrode system with $\mathrm{Pt}$ foil and $\mathrm{Hg} / \mathrm{Hg}_{2} \mathrm{SO}_{4}$ as the counter and reference electrode, respectively. The catalyst ink was prepared by dispersing $5 \mathrm{mg}$ of catalyst powder in $5 \mathrm{~mL}$ of ethanol solution. $15 \mu \mathrm{L}$ of the catalyst ink was dropped onto the surface of glassy carbon electrode (4 mm diameter) and allowed to dry at room temperature. Then, $5 \mu \mathrm{L}$ of $0.05 \mathrm{wt} . \%$ Nafion solution was applied onto the surface of the 
dried catalyst layer to use as the working electrode. Before the electrochemical tests, the working electrode was pretreated by potential sweep between $0.05 \mathrm{~V}$ and $1.2 \mathrm{~V}$ in $0.5 \mathrm{M} \mathrm{N}_{2}$-purged $\mathrm{H}_{2} \mathrm{SO}_{4}$ solution until a stable voltammogram was obtained and impurity was removed completely. The electrochemical surface area (ESA) was determined by the hydrogen desorption peaks in the obtained cyclic voltammograms (CV) curves based on the following equation:

$$
\mathrm{ESA}=\frac{\mathrm{Q}_{\mathrm{H}}}{0.21 \times[\mathrm{Pt}]}
$$

where $\mathrm{Q}_{\mathrm{H}}$ is the charge for hydrogen desorption, $[\mathrm{Pt}]$ is the $\mathrm{Pt}$ loading $\left(\mathrm{mg} \mathrm{cm}^{-2}\right)$ in the working electrode, and $0.21 \mathrm{mC} \mathrm{cm}^{-2}$ represents the charge associated with monolayer adsorption of hydrogen on Pt. The methanol oxidation reaction (MOR) activity was evaluated by $\mathrm{CV}$ at a scan rate of $50 \mathrm{mV} \mathrm{s}^{-1}$ and chronoamperometry (CA) test at a potential of $0.6 \mathrm{~V}$ in $0.5 \mathrm{M} \mathrm{CH}_{3} \mathrm{OH}$ and $0.5 \mathrm{M} \mathrm{H}_{2} \mathrm{SO}_{4}$ solution. All the performance results were normalised to Pt surface area. $\mathrm{CO}$ stripping was conducted in $0.5 \mathrm{M} \mathrm{H}_{2} \mathrm{SO}_{4}$ solution at a scan rate of $10 \mathrm{mV} \cdot \mathrm{s}^{-1}$. Before the $\mathrm{CO}$ stripping test, the electrolyte was bubbled with $\mathrm{CO}$ gas by holding the electrode potential at $90 \mathrm{mV}$ for $30 \mathrm{~min}$, followed by purging $\mathrm{N}_{2}$ gas for 30 min to remove the residual $\mathrm{CO}$. Tafel plots were recorded in potentiostatic mode after the current decayed for 20 s. All the experiments were conducted at room temperature and all potentials were reported with respect to the reversible hydrogen electrode (RHE).

Differential electrochemical mass spectrometry (DEMS) experiment was carried out in a BGM-202 spectrometer (ULVAC, Japan) in vacuum at a heating rate of $5^{\circ} \mathrm{C} \mathrm{min}^{-1}$. Before the measurement, the sample was put in a quartz reactor and heated in $\mathrm{H}_{2} / \mathrm{Ar}$ at $400{ }^{\circ} \mathrm{C}$ for $0.5 \mathrm{~h}$ to remove the impurities. Adsorption of $\mathrm{CO}$ was performed at room temperature by bubbling $\mathrm{CO}$ gas into quartz reactor for $1 \mathrm{~h}$. 
Excessive adsorbate was removed by vacuumizing until no significant change for the baseline could be detected.

\section{Results and discussion}

\subsection{Physical characterization}

The detailed morphology and structure of $\mathrm{N}$-doped graphene (NG) and $\mathrm{B}, \mathrm{N}$ co-doped graphene (BNG) are studied by TEM and HRTEM (Fig. 1). Both NG and BNG samples exhibit thin, transparent and curled structure (Fig. 1A and 1B), which is similar to the typical structure of graphene (Fig. S1 in Supporting Information). The thickness of both NG and BNG samples is $\sim 5 \mathrm{~nm}$ (Fig. 1C and 1D), indicating their multilayered nature, which might be due to the thermal annealing that causes the stacking between graphene layers [31]. Careful observation reveals that the thickness of NG and BNG monolayer is $\sim 0.34 \mathrm{~nm}$, which is also identical to that of pure graphene [32]. All these results indicate that the doping process of foreign $\mathrm{N}$ and $\mathrm{B}$ atoms does not significantly change the morphology graphene sheets.

\section{Fig. 1.}

Fig. 2A shows Raman spectra of the NG and BNG samples. The D peak located at $1361 \mathrm{~cm}^{-1}$ [33] is a signature of disorder-induced vibration mode and the $\mathrm{G}$ peak at $1580 \mathrm{~cm}^{-1}$ [34] is commonly observed for the $\mathrm{sp}^{2}$ bonded graphitic carbons [35]. Therefore, the intensity ratio of D peak and G peak $\left(\mathrm{I}_{\mathrm{D}} / \mathrm{I}_{\mathrm{G}}\right)$ is a factor for judging the degree of graphitization of carbon. The $\mathrm{I}_{\mathrm{D}} / \mathrm{I}_{\mathrm{G}}$ ratio increases from 0.85 for NG to 1.03 for BNG, which suggests an increase in the defect sites due to the boron atom doping into NG. This increase in defect sites will accelerate the subsequent deposition of Pt nanoparticles. The 
chemical composition of NG and BNG samples is characterized by XPS and the results are shown in Fig. 2B and 2C. In Fig. 2B, the $\mathrm{N}$ 1s peak of NG is deconvoluted into two kinds of nitrogen: the pyridinic $\mathrm{N}$ (398.3 eV [36]) and the pyrrolic $\mathrm{N}$ (400.3 eV [36]). In comparison with NG, the deconvoluted results of BNG sample exhibit a new peak located at $397.6 \mathrm{eV}$ [37], which can be assigned to the N-B bond with boron atomic percentage of $3.7 \%$, indicating that boron atoms have already been bonded to NG. It is further revealed that the atomic content of $\mathrm{N}$ in $\mathrm{NG}$ and $\mathrm{BNG}$ samples is around $2.6 \%$ and $2.4 \%$, respectively. Moreover, the percentage of pyrrolic N decreases significantly from $13.3 \%$ for NG to $6.7 \%$ for $\mathrm{BNG}$, while that of pyridinic $\mathrm{N}$ increases from $86.7 \%$ for $\mathrm{NG}$ to $89.8 \%$ for BNG. These results indicate that the pyrrolic $\mathrm{N}$ can easily react with boron atoms and transforms into the pyridinic $\mathrm{N}$, because the pyrrolic $\mathrm{N}$ is less stable [38]. Thus, the pyrrolic nitrogen plays an important role in the boron doping process, which should be the main reaction site with the mechanism shown in Fig. S2. The B 1s peak for BNG (Fig. 2C), whose location (191.0 eV) is higher than that of pure boron (187.0 eV [39]), can be deconvoluted to largely the N-B-C [40] species as well as a small amount of B-C-O species [41].

\section{Fig. 2.}

The detailed textural features of support materials are determined by $\mathrm{N}_{2}$ adsoption/desorption isotherms of graphene, NG and BNG (Fig. 3). All samples show similar type IV adsorption isotherms with a significant hysteresis loop type $\mathrm{H}_{3}$, which is correlated with slit-shaped mesopores possibly between parallel layers [42]. The pore size distributions of the samples (inset of Fig. 3) show a main distribution of 2-40 nm, indicating that these materials are composed of a large amount of mesopores [43]. Moreover, the BET surface area of graphene, NG and BNG is $315.7 \mathrm{~m}^{2} \mathrm{~g}^{-1}, 326.5 \mathrm{~m}^{2} \mathrm{~g}^{-1}$ and 328.8 $\mathrm{m}^{2} \mathrm{~g}^{-1}$, respectively, which are close to each other. These results indicate that boron and nitrogen doping 
does not significantly change the textural features of graphene.

\section{Fig. 3.}

The TEM images of $\mathrm{Pt} / \mathrm{NG}$ and $\mathrm{Pt} / \mathrm{BNG}$ catalysts are shown in Fig. 4. It is clear that Pt nanoparticles are uniformly distributed on the NG and BNG supports (Fig. 4A and 4B), confirming that the Pt nanoparticles have been successfully loaded on the supports. From the HRTEM images (Fig. 4C and 4D), the crystalline lattice planes of Pt nanoparticles can be observed. The crystalline lattice planes have the same spacing of $0.227 \mathrm{~nm}$ for the $\mathrm{Pt} / \mathrm{NG}$ and $\mathrm{Pt} / \mathrm{BNG}$ catalysts, suggesting that the crystalline structure of $\mathrm{Pt}$ nanoparticles does not change for $\mathrm{Pt} / \mathrm{NG}$ and $\mathrm{Pt} / \mathrm{BNG}$ catalysts. However, the average particle size of $\mathrm{Pt} / \mathrm{BNG}$ catalyst is $2.3 \pm 0.2 \mathrm{~nm}$, which is lower than that of $\mathrm{Pt} / \mathrm{NG}(2.5 \pm 0.2 \mathrm{~nm})$ catalyst (Fig. 4E and 4F), in agreement with the XRD results (Fig. S3.). Moreover, the Pt/BNG catalyst shows a narrower size distribution than the Pt/NG catalyst. This improved dispersion can be ascribed to the more defects sites in the BNG support that serve as the preferred sites for Pt nanoparticles anchoring, which is consistent with the observation in Raman results. The Pt loading for $\mathrm{Pt} / \mathrm{NG}$ and $\mathrm{Pt} / \mathrm{BNG}$ catalysts is determined by ICP-MS to be 38.9 wt.\% and 39.2 wt.\%, respectively, which is largely consistent with the designed value.

\section{Fig. 4.}

\subsection{Electrocatalytic activity}

The electrochemical behavior of $\mathrm{Pt} / \mathrm{NG}, \mathrm{Pt} / \mathrm{BNG}$ and $\mathrm{PtRu} / \mathrm{C}$ catalysts is firstly studied by $\mathrm{CV}$ in $0.5 \mathrm{M} \mathrm{N}_{2}$-saturated $\mathrm{H}_{2} \mathrm{SO}_{4}$ solution at the scan rate of $50 \mathrm{mV} \mathrm{s}^{-1}$ (Fig. 5A). Based on the hydrogen desorption peaks, the electrochemical surface area (ESA) of Pt/BNG catalyst is calculated to be $70.6 \mathrm{~m}^{2}$ $\mathrm{g}_{\mathrm{Pt}}{ }^{-1}$, which is 1.15 times and 1.21 times that of Pt/NG catalyst $\left(61.2 \mathrm{~m}^{2} \mathrm{~g}_{\mathrm{Pt}}{ }^{-1}\right)$ and $\mathrm{PtRu} / \mathrm{C}\left(58.5 \mathrm{~m}^{2} \mathrm{~g}_{\mathrm{Pt}}{ }^{-1}\right)$, 
respectively. These results should be ascribed to the introduction of boron atoms, which generates additional defect sites for the uniform deposition of Pt nanoparticles as revealed by the TEM images (Fig. 4) [34].

The electrocatalytic activities of $\mathrm{Pt} / \mathrm{NG}, \mathrm{Pt} / \mathrm{BNG}$ and $\mathrm{PtRu} / \mathrm{C}$ catalysts towards the MOR are characterized by $\mathrm{CV}$ and $\mathrm{CA}$ in a solution of $0.5 \mathrm{M} \mathrm{H}_{2} \mathrm{SO}_{4}$ and $0.5 \mathrm{M}$ methanol. The $\mathrm{CV}$ curves exhibit the well-known features of methanol oxidation on Pt catalysts (Fig. 5B). The forward peak current density for Pt/BNG is $2.46 \mathrm{~mA} \mathrm{~cm}^{-2}$, which is 1.56 times and 1.63 times that for $\mathrm{Pt} / \mathrm{NG}\left(1.58 \mathrm{~mA} \mathrm{~cm}^{-2}\right)$ and PtRu/C (1.51 $\left.\mathrm{mA} \mathrm{cm}^{-2}\right)$, respectively. For the CA curves (Fig. 5C), the current density for Pt/NG, $\mathrm{Pt} / \mathrm{BNG}$ and $\mathrm{PtRu} / \mathrm{C}$ catalysts decreases rapidly in the intial stage, which should be due to the formation of poisoning intermediates (mainly $\mathrm{CO}_{\mathrm{ads}}$ or $\mathrm{CHO}_{\mathrm{ads}}$ ) during the methanol oxidation process [44]. After $1000 \mathrm{~s}$, however, the current density is $0.18 \mathrm{~mA} \mathrm{~cm}^{-2}$ for $\mathrm{Pt} / \mathrm{BNG}$, which is 3.0 times and 3.6 times higher than that for $\mathrm{Pt} / \mathrm{NG}\left(0.06 \mathrm{~mA} \mathrm{~cm}^{-2}\right)$ and $\mathrm{PtRu} / \mathrm{C}\left(0.05 \mathrm{~mA} \mathrm{~cm}{ }^{-2}\right)$, respectively. Meanwhile, the mass activity of $\mathrm{Pt} / \mathrm{BNG}$ catalyst is also significantly higher than that of $\mathrm{Pt} / \mathrm{NG}$ and $\mathrm{PtRu} / \mathrm{C}$ catalysts (Fig. S4). All these results definitely indicate that the Pt/BNG catalyst has higher methanol oxidation activity than Pt/NG and PtRu/C.

The electrochemical stabilities of $\mathrm{Pt} / \mathrm{NG}$ and $\mathrm{Pt} / \mathrm{BNG}$ catalysts are evaluated by the continuous potential cycling between $0.05 \mathrm{~V}$ and $1.2 \mathrm{~V}$. Fig. 5D and 5E present the voltammograms at different cycles for $\mathrm{Pt} / \mathrm{NG}$ and $\mathrm{Pt} / \mathrm{BNG}$ catalysts. It can be observed that the hydrogen adsorption/desorption peaks of both $\mathrm{Pt} / \mathrm{NG}$ and $\mathrm{Pt} / \mathrm{BNG}$ catalysts degrade during the cycling process. The degradation of ESA normalized by the initial values of $\mathrm{Pt} / \mathrm{NG}$ and $\mathrm{Pt} / \mathrm{BNG}$ catalysts is plotted along with the cycling number in Fig. 5F. After 1000 cycles, the Pt/NG catalyst maintains $75.71 \%$ of its initial ESA, while $79.24 \%$ of 
the initial ESA remains for the Pt/BNG catalyst. This result indicates that the $\mathrm{Pt} / \mathrm{BNG}$ catalyst has slightly higher stability than $\mathrm{Pt} / \mathrm{NG}$, which should be due to the higher interaction between $\mathrm{Pt}$ nanoparticles and BNG support that inhibits the aggregation and dissolution of Pt nanoparticles during the potential cycling.

\section{Fig. 5.}

\subsection{Mechanism}

In order to investigate the enhancing mechanism of Pt/BNG catalyst towards the MOR, Tafel plots for $\mathrm{Pt} / \mathrm{NG}$ and $\mathrm{Pt} / \mathrm{BNG}$ catalysts are measured and shown in Fig. 6. Each Tafel plot can be divided into the low and high polarization regions. It has been revealed that, at the potential of $0.4 \mathrm{~V} \sim 0.5 \mathrm{~V}$ [45], the methanol oxidation process on Pt surface involves the dissociative chemisorption of methanol to give a Pt-COH species as follows [46]:

$$
\begin{gathered}
\mathrm{Pt}+\mathrm{CH}_{3} \mathrm{OH} \rightarrow \mathrm{Pt}-\mathrm{CH}_{2} \mathrm{OH}+\mathrm{H}^{+}+\mathrm{e}^{-} \\
\mathrm{Pt}-\mathrm{CH}_{2} \mathrm{OH} \rightarrow \mathrm{Pt}-\mathrm{CHOH}+\mathrm{H}^{+}+\mathrm{e}^{-} \\
\mathrm{Pt}-\mathrm{CHOH} \rightarrow \mathrm{Pt}-\mathrm{COH}+\mathrm{H}^{+}+\mathrm{e}^{-}
\end{gathered}
$$

During these processes, the first dehydrogenation step is the rate determining step. For the low polarization region, the Tafel slope for $\mathrm{Pt} / \mathrm{NG}$ and $\mathrm{Pt} / \mathrm{BNG}$ catalysts is $104.0 \mathrm{mV} \mathrm{dec}{ }^{-1}$ and $75.8 \mathrm{mV}$ $\mathrm{dec}^{-1}$, respectively. The lower slope for Pt/BNG suggests the higher methanol dehydrogenation rate. The transfer coefficient $\beta$ and exchange current density $i^{0}$ for methanol dehydrogenation processes are obtained from the Tafel plots based on the Butler-Volmer formula:

$$
\eta=-\frac{2.3 R T}{\beta F n} \lg i^{0}+\frac{2.3 R T}{\beta F n} \lg i
$$


where $\eta$ is overpotential, $R$ gas constant $\left(8.314 \mathrm{~J} \mathrm{~K}^{-1}\right), T$ temperature, $F$ Faraday constant $(96500 \mathrm{C}$ $\left.\mathrm{mol}^{-1}\right), n$ the number of transferred electrons. Thus obtained $\beta$ and $i^{0}$ values of Pt/NG and Pt/BNG catalysts are $0.3,6.3 \times 10^{-8} \mathrm{~A} \mathrm{~cm}^{-2}$ and $0.4,5.7 \times 10^{-6} \mathrm{~A} \mathrm{~cm}^{-2}$, respectively, clearly indicating the higher methanol dehydrogenation rate for Pt/BNG catalyst.

\section{Fig. 6.}

In the high polarization region, the MOR is complicated by the formation of $\mathrm{CO}_{\text {ads }}$ poisoning intermediate and oxygen-containing species, formaldehyde, and fomic acide et al. However, the poisoning intermediate $\left(\mathrm{CO}_{\mathrm{ads}}\right)$ is attached to $\mathrm{Pt}$ surface and blocked subsequent reaction. As a result, the Tafel slopes are different from those in the low potential region, indicating that the varied rate-determining step. The most likely rate determining step in the high polarization region should be the oxidative removal of adsorbed $\mathrm{CO}_{\text {ads }}$ [44-47]:

$$
\begin{gathered}
\mathrm{Pt}-\mathrm{COH} \rightarrow \mathrm{Pt}-\mathrm{CO}+\mathrm{H}^{+}+\mathrm{e}^{-} \\
\mathrm{Pt}-\mathrm{CO}+\mathrm{OH}_{\mathrm{ad}} \rightarrow \mathrm{Pt}+\mathrm{CO}_{2}+\mathrm{H}_{2} \mathrm{O}
\end{gathered}
$$

The Tafel slope of Pt/BNG catalyst is less than that of $\mathrm{Pt} / \mathrm{NG}$ in these potential ranges, indicating that the higher rate of $\mathrm{CO}_{\text {ads }}$ removal. To verify the ability of $\mathrm{CO}_{\text {ads }}$ removal, $\mathrm{CO}$ stripping test is carried out in $0.5 \mathrm{M} \mathrm{H}_{2} \mathrm{SO}_{4}$ solution (Fig. 7A). The onset and peak potentials for Pt/BNG catalyst shift negatively $30 \mathrm{mV}$ and $10 \mathrm{mV}$, respectively, in comparison with Pt/NG catalyst, confirming the enhanced $\mathrm{CO}$ tolerance by the BNG support material.

DEMS is used to analyze the adsorption strength of $\mathrm{CO}_{\text {ads }}$ on $\mathrm{Pt}$ surface for $\mathrm{Pt} / \mathrm{NG}$ and $\mathrm{Pt} / \mathrm{BNG}$ catalysts (Fig. 7B). Apparently, $\mathrm{CO}_{\text {ads }}$ is desorbed at $170{ }^{\circ} \mathrm{C}$ for $\mathrm{Pt} / \mathrm{BNG}$ catalyst, which is significantly lower than that for $\mathrm{Pt} / \mathrm{NG}$ catalyst $\left(300{ }^{\circ} \mathrm{C}\right)$. The low desorption temperature for $\mathrm{Pt} / \mathrm{BNG}$ catalyst 
illustrates the weaker adsorption energy between Pt and $\mathrm{CO}$, which should be attributed to the boron doping into the NG support.

\section{Fig. 7.}

XPS is employed to analyze the underlying mechanism of high dehydrogenation rate and CO tolerance for Pt/BNG catalyst. Fig. 8A shows Pt 4f XPS spectra for Pt/NG and Pt/BNG catalysts. The Pt 4f peak for Pt/BNG catalyst $(71.1 \mathrm{eV})$ shifts negatively by $0.3 \mathrm{eV}$ compared to Pt/NG $(71.4 \mathrm{eV})$, indicating the higher electron density of $\mathrm{Pt}$, which should be ascribed to the electron transfer to $\mathrm{Pt}$ from the $\mathrm{B}$ atoms doped in BNG support that have lower electronegativity. This electron transfer lowers the d-band center of Pt, which decreases the bond energy of C-H bond [26,48], and weakens the adsorption of poisoning intermediates according to the d-band center theory by Nørskov [25]. Thus, both the methanol dehydrogenation and the $\mathrm{CO}$ oxidation rates on the Pt/BNG catalyst are accelerated $[27,49]$. Moreover, the Pt/BNG catalyst presents higher metallic Pt content (77.43\%) than Pt/NG (57.83\%), which should be attributed to the fact that B doping can transfer electron to Pt and increase its electron density because $\mathrm{B}$ atoms have lower electronegativity [50,51]. The higher metallic Pt content indicates that BNG support facilitates the formation of metallic $\mathrm{Pt}$, which is beneficial to the methanol electrooxidation by providing more active sites for the reactions of methanol dehydrogenation and adsorbed intermediates removal. This mechanism is highly different from that of Pt/NG catalyst [52], which raises the d-band center of $\mathrm{Pt}$ by the doped nitrogen with high electronegtivity, thus leading to strengthened chemisorption of reaction intermediates.

In addition to the mechanism of weakening the adsorption strength of reaction intermediates, the

XPS results also show that the $\mathrm{O}$ atomic content is $12.89 \%$ and $13.06 \%$ for $\mathrm{Pt} / \mathrm{NG}$ and $\mathrm{Pt} / \mathrm{BNG}$ (Fig. 8B), 
respectively. According to the deconvoluted results of $\mathrm{O}$ 1s spectra, the content of C-OH group at 533.3 $\mathrm{eV}$ for $\mathrm{Pt} / \mathrm{BNG}$ is $16.7 \%$, which is higher than that for $\mathrm{Pt} / \mathrm{NG}(14.01 \%)$, which might be due to the B-C-O bond introduced by boron atoms, forming a new defect site of oxygen species. The presence of more $\mathrm{C}-\mathrm{OH}$ groups on the $\mathrm{BNG}$ support can promote the oxidation of $\mathrm{CO}_{\mathrm{ad}}$ on the $\mathrm{Pt}$ active sites via the bifunctional mechanism [27]. As a result, the high $\mathrm{CO}$ tolerance of $\mathrm{Pt} / \mathrm{BNG}$ catalyst is attibuted to the reduced $\mathrm{CO}$ adsorption energy by lowering the d-band center of $\mathrm{Pt}$ and also the abundant oxygen-containing functional groups on the BNG surface from the high defects level as revealed by the Raman results.

\section{Fig. 8.}

\section{Conclusions}

We have prepared the boron, nitrogen co-doped graphene (BNG) by the thermal annealing of nitrogen doped graphene and boric acid, which is employed as the support material to disperse Pt nanoparticles by a microwave-assisted polyol reduction procedure. Boron atoms are incorporated into the nitrogen doped graphene mainly in the form of B-N-C and B-C-O bonds, which facilitates the uniform dispersion of $\mathrm{Pt}$ nanoparticles. Thus, the obtained Pt/BNG catalyst has 1.15 times and 1.21 times higher electrochemical surface area in comparison to $\mathrm{Pt} / \mathrm{NG}$ catalyst and $\mathrm{PtRu} / \mathrm{C}$, respectively. Furthermore, the Pt/BNG catalyst exhibits greatly enhanced catalytic activity towards the methanol oxidation reaction, which is 3.0 times and 3.6 times higher thant that of $\mathrm{Pt} / \mathrm{NG}$ and $\mathrm{PtRu} / \mathrm{C}$ catalyst, respectively. The superior catalytic properties of Pt/BNG catalyst is largely attributed to the increased electron density and lowered d-band center of Pt induced by boron atoms doping, which accelerate the 
dehydrogenation of methanol and weaken the $\mathrm{CO}$ intermediate poisoning. Meanwhile, the nitrogen doping also enhances the oxidation removal of $\mathrm{CO}$ intermediate by the bifunctional mechanism. The synergetic contribution of nitrogen and boron co-doping leads to the MOR activity enhancement of Pt/BNG catalyst. Our study provides a new strategy for designing and preparing fuel-cell catalyst supports with tailorable cocatalytic properties.

\section{Acknowledgements}

This work was supported by the National Science Foundation of China under contract No. 21376057 and 21433003.

\section{References}

[1] P. Wu, Y. Y. Huang, L. Q. Zhou, Y. B. Wang, Y. K. Bu, J. N. Yao, Nitrogen-doped graphene supported highly dispersed palladium-lead nanoparticles for synergetic enhancement of ethanol electrooxidation in alkaline medium, Electrochim. Acta 152 (2015) 68.

[2] G. Wu, R. Swaidan, D. Y. Li, N. Li, Enhanced methanol electro-oxidation activity of PtRu catalysts supported on heteroatom-doped carbon, Electrochim. Acta 53 (2008) 7622.

[3] A. K. Geim, K. S. Novoselov, The Rise of Graphene, Nat. Mater. 6 (2007) 183.

[4] O. V. Prezhdo, P. V. Kamat, G. C. Schatz, Virtual issue: graphene and functionalized graphene, J. Phys. Chem. C 115 (2011) 3195.

[5] D. S. Geng, Y. H. Hu, Y. L. Li, R.Y. Li, X. L. Sun, One-pot solvothermal synthesis of doped graphene with the designed nitrogen type used as a Pt support for fuel cells, Electrochem. Commun. 22 
(2012) 65.

[6] A. H. A. M. Videla, L. G. Osmieri, R. A. M. Esfahani, J. Q. Zeng, C. Francia, S. Specchia, The use of $\mathrm{C}-\mathrm{MnO}_{2}$ as hybrid precursor support for a $\mathrm{Pt} / \mathrm{C}-\mathrm{Mn}_{\mathrm{x}} \mathrm{O}_{1+\mathrm{x}}$ catalyst with enhanced activity for the methanol oxidation reaction (MOR), Catalysts 5 (2015) 1399.

[7] J. Zeng, C. Francia, C. Gerbaldi, V. Baglio, S. Specchia, A. S. Aricò, P. Spinelli, Hybrid ordered mesoporous carbons doped with tungsten trioxide as supports for Pt electrocatalysts for methanol oxidation reaction, Electrochim. Acta 94 (2013) 80.

[8] S. Sharma, A. Ganguly, P. Papakonstantinou, X. Miao, M. Li, J. L. Hutchison, M. Delichatsios, S. Ukleja, Rapid microwave synthesis of $\mathrm{CO}$ tolerant reduced graphene oxide-supported platinum electrocatalysts for oxidation of methanol, J. Phys. Chem. C 114 (2010) 19459.

[9] Z. L. Liu, F. B. Su, X. H. Zhang, S. W. Tay, Preparation and characterization of PtRu nanoparticles supported on nitrogen-doped porous carbon for electrooxidation of methanol, ACS Appl. Mater. Interfaces 3 (2011) 3824.

[10] D. P. He, Y. L. Jiang, H. F. Lv, M. Pan, S. C. Mu, Nitrogen-doped reduced graphene oxide supports for noble metal catalysts with greatly enhanced activity and stability, Appl. Catal. B: Environ. $132-133(2013) 379$.

[11] S. C. Mu, X. Chen, R. H. Sun, X. B. Liu, H. Liu, D. P. He, K. Cheng, Nano-size boron carbide intercalated graphene as high performance catalyst supports and electrodes for PEM fuel cells, Carbon 103 (2016) 449.

[12] D. W. Wang, F. Li, Z. G. Chen, G. Q. Lu, H. M. Cheng, Synthesis and electrochemical property of boron-doped mesoporous carbon in supercapacitor, Chem. Mater. 20 (2008) 7195. 
[13] Z. Yang, Z. Yao, G. F. Li, G. Y. Fang, H. G. Nie, Z. Liu, X. M. Zhou, X. A. Chen, S. M. Huang, Sulfur-doped graphene as an efficient metal-free cathode catalyst for oxygen reduction, ACS Nano 6 (2011) 205.

[14] D. S.Yang, D. Bhattacharjya, S. Inamdar, J. Park, J. S. Yu, Phosphorus-doped ordered mesoporous carbons with different lengths as efficient metal-free electrocatalysts for oxygen reduction reaction in alkaline media, J. Am. Chem. Soc. 134 (2012) 16127.

[15] S. U. Lee, R. V. Belosludov, H. Mizuseki, Y. Kawazoe, Designing nanogadgetry for nanoelectronic devices with nitrogen-doped capped carbon nanotubes, Small 5 (2009) 1769.

[16] B. Xiong, Y. K. Zhou, R. O’Hayre, Z. P. Shao, Facile single-step ammonia heat-treatment and quenching process for the synthesis of improved Pt/N-graphene catalysts, Appl. Surf. Sci. 266 (2013) 433.

[17] Q. Liu, H. Y. Zhang, H. W. Zhong, S. M. Zhang, S. L. Chen, N-doped graphene/carbon composite as non-precious metal electrocatalyst for oxygen reduction reaction, Electrochim. Acta 81(2012) 313.

[18] Y. K. Zhou, K. Neyerlin, T. S. Olson, S. Pylypenko, J. Bult, H. N. Dinh, T. Gennett, Z. P. Shao, R. O’Hayre, Enhancement of Pt and Pt-alloy fuel cell catalyst activity and durability via nitrogen-modified carbon supports, Energy Environ. Sci. 3 (2010) 1437.

[19] L. S. Zhang, X. Q. Liang, W. G. Song, Z. Y. Wu, Phys. Identification of the nitrogen species on N-doped graphene layers and Pt/NG composite catalyst for direct methanol fuel cell, Chem. Chem. Phys. $12(2010) 12055$.

[20] S. F. Zheng, J. S. Hu, L. S. Zhong, L. J. Wan, W. G. Song, In situ one-step method for preparing carbon nanotubes and Pt composite catalysts and their performance for methanol oxidation, J. Phys. 
Chem. C $111(2007) 11174$.

[21] Y. Y. Zhao, Y. K. Zhou, B. Xiong, J. Wang, X. Chen, R. O’Hayre, Z. P. Shao, Facile single-step preparation of $\mathrm{Pt} / \mathrm{N}$-graphene catalysts with improved methanol electrooxidation activity, J. Solid State Electrochem. 17 (2013) 1089.

[22] J. Cao, Y. Y. Chu, X. Y. Tan, Pt/XC-72 catalysts coated with nitrogen-doped carbon (Pt/XC-72@C-N) for methanol electro-oxidation, Mater. Chem. Phys. 144 (2014) 17.

[23] K. Christmann, The Adsorption and reaction of methanol on Pd (100). I. Chemisorption and condensation, J. Chem. Phys. 76 (1982) 6308.

[24] X. J. Wang, L. Chen, B. T. Li, A density functional theory study of methanol dehydrogenation on the $\operatorname{PtPd}_{3}$ (111) surface, Int. J. Hydrogen Energy. 40 (2015) 9656.

[25] B. Hammer, J. K. Norskov, Electronic factors determining the reactivity of metal surfaces, Surf. Sci. 343 (1995) 211.

[26] J. R. Kitchin, J. K. Norskov, M. A. Barteau, J. G. Chen, Role of strain and ligand effects in the modification of the electronic and chemical properties of bimetallic surfaces, Phys. ReV. Lett. 93 (2004) 156801.

[27] X. J. Wang, L. Chen, B. T. Li, A density functional theory study of methanol dehydrogenation on the PtPd3(111) surface, Int. J. Hydrogen Energy 40 (2015) 9656.

[28] S. Y. Wang, L. P. Zhang, Z. H. Xia, A. Roy, D. W. Chang, J. B. Baek, L. M. Dai, BCN graphene as efficient metal-free electrocatalyst for the oxygen reduction reaction, Angew. Chem. Int. Ed. 51 (2012) 4209.

[29] C. H. Choi, M. W. Chung, H. C. Kwon, S. H. Park, S. I. Woo, B, N- and P, N-doped graphene as 
highly active catalysts for oxygen reduction reactions in acidic media, J. Mater. Chem. A 1(2013) 3694.

[30] W. S. Hummers, R. E. Offeman, Preparation of graphitic oxide, J. Am. Chem. Soc. 80 (1958) 1339.

[31] M. S. Wietecha, J. Zhu, G. H. Gao, N. Wang, H. Feng, M. L. Gorring, M. L. Kasner, S. F. Hou, Platinum nanoparticles anchored on chelating group-modified graphene for methanol oxidation, J. Power Sources 198 (2012) 30.

[32] W. Ding, Z. D. Wei, S. G. Chen, X. Q. Qi, T. Yang, J. S. Hu, D. Wang, L. J. Wan, S. F. Alvi, L. Li, Space-confinement-induced synthesis of pyridinic-and pyrrolic-nitrogen-doped graphene for the catalysis of oxygen reduction, Angew. Chem. Int. Ed. 52 (2013) 11755.

[33] G. H. Yang, Y. Q. Li, R. K. Rana, J. J. Zhu, Pt-Au/nitrogen-doped graphene nanocomposites for enhanced electrochemical activities, J. Mater. Chem. A 1 (2013) 1754.

[34] J. Xu, S. L. Gai, F. He, N. Niu, P. Gao, Y. J. Chen, P. P. Yang, A Sandwich-type three-dimensional layered double hydroxide nanosheet array/graphene composite: fabrication and high supercapacitor performance, J. Mater. Chem. A 2 (2014) 1022.

[35] J. Yan, H. Meng, F. Y. Xie, X. L. Yuan, W. D. Yu, W. R. Lin, W. P. Ouyang, D. S. Yuan, Metal free nitrogen doped hollow mesoporous graphene-analogous spheres as effective electrocatalyst for oxygen reduction reaction, J. Power Sources 245 (2014) 772.

[36] B. Xiong, Y. K. Zhou, Y. Y. Zhao, J. Wang, X. Chen, R. O’Hayre, Z. P. Shao, The use of nitrogen-doped graphene supporting $\mathrm{Pt}$ nanoparticles as a catalyst for methanol electrocatalytic oxidation, Carbon 52 (2013) 181.

[37] J. T. Jin, F. P. Pan, L. H. Jiang, X. G. Fu, A. M. Liang, Z. Y. Wei, J. Y. Zhang, G. Q. Sun, Catalyst-free synthesis of crumpled boron and nitrogen co-doped graphite layers with tunable bond 
structure for oxygen reduction reaction, ACS Nano 8 (2014) 3313.

[38] B. Xiao, J. P. Boudou, K. M. Thomas, Reactions of nitrogen and oxygen surface groups in nanoporous carbons under inert and reducing atmospheres, Langmuir 21 (2005) 3400.

[39] Z. H. Sheng, H. L.Gao, W. J. Bao, F. B. Wang, X. H. Xia, Synthesis of boron doped graphene for oxygen reduction reaction in fuel cells, J. Mater. Chem. 22 (2012) 390.

[40] L. J. Cui, L. Song, C. H. Jin, D. Jariwala, D. X. Wu, Y. J. Li, A. Srivastava, Z. F. Wang, K. Storr, L. Balicas, F. Liu, P. M. Ajayan, Atomic layers of hybridized boron nitride and graphene domains, Nat. Mater. 9 (2010) 430.

[41] Y. Zhao, L. J. Yang, S. Chen, X. Z. Wang, Y. W. Ma, Q. Wu, Y. F. Jiang, W. J. Qian, Z. Hu, Can boron and nitrogen co-doping improve oxygen reduction reaction activity of carbon nanotubes? J. Am. Chem. Soc. 135 (2013) 1201.

[42] Y. Zhang, B. L. Tao, W. Xing, L. Zhang, Q. Z. Xue , Z. F. Yan, Sandwich-like nitrogen-doped porous carbon/graphene nanoflakes with high-rate capacitive performance, Nanoscale 8 (2016) 7889.

[43] X. C. Qiao, S. J. Liao, C. H. You, R. Chen, Phosphorus and nitrogen dual doped and simultaneously reduced graphene oxide with high surface area as efficient metal-free electrocatalyst for oxygen reduction, Catalysts 5 (2015) 981.

[44] A. Kabbabi, R. Faure, R. Durand, B. Beden, F. Hahn, J. M. Leger, C. Lamy, In situ FTIRS study of the electrocatalytic oxidation of carbon monoxide and methanol at platinum-ruthenium bulk alloy electrodes, J. Electroanal. Chem. 444 (1998) 41.

[45] T. Iwasita, Electrocatalysis of methanol oxidation, Electrochim. Acta 47 (2002) 3663.

[46] R. Manoharan, J. B. Goodenough, Methanol oxidation in acid on ordered NiTi, J. Mater. Chem. 2 
(1992) 875.

[47] K. I. B. Eguiluz, G. R. Salazar-Banda, D. Miwa, S. A. S. Machado, L. A. Avaca, Effect of the catalyst composition in the $\mathrm{Pt}_{\mathrm{x}}(\mathrm{Ru}-\mathrm{Ir})_{1-\mathrm{x}} / \mathrm{C}$ system on the electro-oxidation of methanol in acid media, $\mathrm{J}$. Power Sources 179 (2008) 42.

[48] J. R. Kitchin, J. K. Norskov, M. A. Barteau, J. G. Chen, Modification of the surface electronic and chemical properties of Pt (111) by subsurface 3d transition metals, J. Chem. Phys. 120 (2004) 10240.

[49] H. S Wang, L. Alden, F. J. DiSalvo, H. D. AbrunA, Electrocatalytic mechanism and kinetics of SOMs oxidation on ordered PtPb and PtBi intermetallic compounds: DEMS and FTIRS study, Phys. Chem. Chem. Phys. 10 (2008) 3739.

[50] Y. R. Sun, C. Y. Du, M. C. An, L. Du, Q. Tan, C. T. Liu, Y. Z. Gao, G. P. Yin, Boron-doped graphene as promising support for platinum catalyst with superior activity towards the methanol electrooxidation reaction, J. Power Sources 300 (2015) 245.

[51] Q. Tan, C.Y. Du, Y. R. Sun, L. Du, G. P. Yin, Y. Z. Gao, Nickel-doped ceria nanoparticles for promoting catalytic activity of Pt/C for ethanol electrooxidation, J. Power Sources 263 (2014) 310.

[52] J. Kua, W. A. Goddard, Oxidation of methanol on 2nd and 3rd row group VIII transition metals (Pt, Ir, Os, Pd, Rh, and Ru): application to direct methanol fuel cells, J. Am. Chem. Soc. 121 (1999) 10928. 


\section{Figure captions:}

Fig. 1. TEM and HRTEM images of $\mathrm{NG}(\mathrm{A}, \mathrm{C})$ and $\mathrm{BNG}(\mathrm{B}, \mathrm{D})$ samples.

Fig. 2. Raman spectrum of NG and BNG (A), N 1s XPS spectra for NG and BNG (B), and B 1s XPS spectra for BNG $(\mathrm{C})$.

Fig. 3. $\mathrm{N}_{2}$ adsoption/desorption isotherms of graphene (A), $\mathrm{NG}(\mathrm{B})$ and $\mathrm{BNG}(\mathrm{C})$ and $\mathrm{BJH}$ pore size distribution (inset).

Fig. 4. TEM and HRTEM images of $\mathrm{Pt} / \mathrm{NG}(\mathrm{A}, \mathrm{C})$ and $\mathrm{Pt} / \mathrm{BNG}(\mathrm{B}, \mathrm{D})$ catalysts, size distribution of $\mathrm{Pt} / \mathrm{NG}(\mathrm{E})$ and Pt/BNG (F) catalysts.

Fig. 5. $\mathrm{CV}$ curves (specific activity) of $\mathrm{Pt} / \mathrm{NG}, \mathrm{Pt} / \mathrm{BNG}$ and $\mathrm{PtRu} / \mathrm{C}$ catalysts in $0.5 \mathrm{M} \mathrm{H}_{2} \mathrm{SO}_{4}(\mathrm{~A}), 0.5 \mathrm{M}$ $\mathrm{H}_{2} \mathrm{SO}_{4}+0.5 \mathrm{M} \mathrm{CH}_{3} \mathrm{OH}$ solution (B), CA curves of Pt/NG, Pt/BNG and PtRu/C catalysts in $0.5 \mathrm{M} \mathrm{H}_{2} \mathrm{SO}_{4}$ $+0.5 \mathrm{M} \mathrm{CH} 3 \mathrm{OH}$ solution (C), stability of Pt/NG (D), Pt/BNG (E) for the different cycles in $0.5 \mathrm{M}$ $\mathrm{H}_{2} \mathrm{SO}_{4}$ solution at a scan rate of $50 \mathrm{mV} \mathrm{s}^{-1}$, and Normalized ESA of Pt/NG and Pt/BNG catalysts with the number of $\mathrm{CV}$ cycles in $0.5 \mathrm{M} \mathrm{H}_{2} \mathrm{SO}_{4}$ solution $(\mathrm{F})$.

Fig. 6. Tafel plots of $\mathrm{Pt} / \mathrm{NG}(\mathrm{A})$ and $\mathrm{Pt} / \mathrm{BNG}(\mathrm{B})$ in $0.5 \mathrm{M} \mathrm{H}_{2} \mathrm{SO}_{4}+0.5 \mathrm{M} \mathrm{CH}_{3} \mathrm{OH}$ solution.

Fig. 7. $\mathrm{CO}$ stripping curves in $0.5 \mathrm{M} \mathrm{H}_{2} \mathrm{SO}_{4}$ solution (A), DEMS for $\mathrm{CO}$ desorption (B) on Pt/NG and Pt/BNG catalysts.

Fig. 8. Pt 4f (A) and O1s (B) XPS spectra of Pt/NG and Pt/BNG catalysts. 

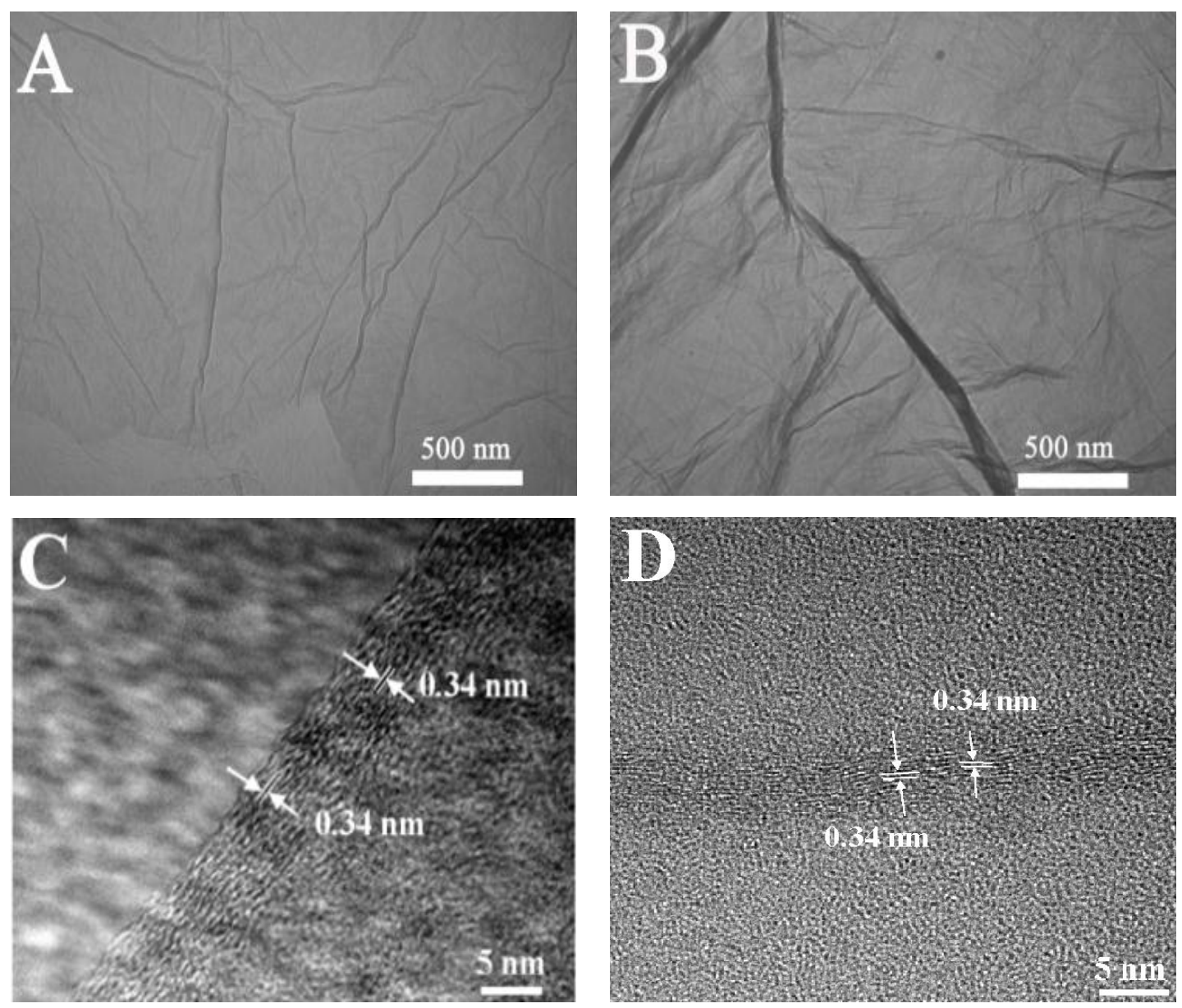

Fig. 1. 

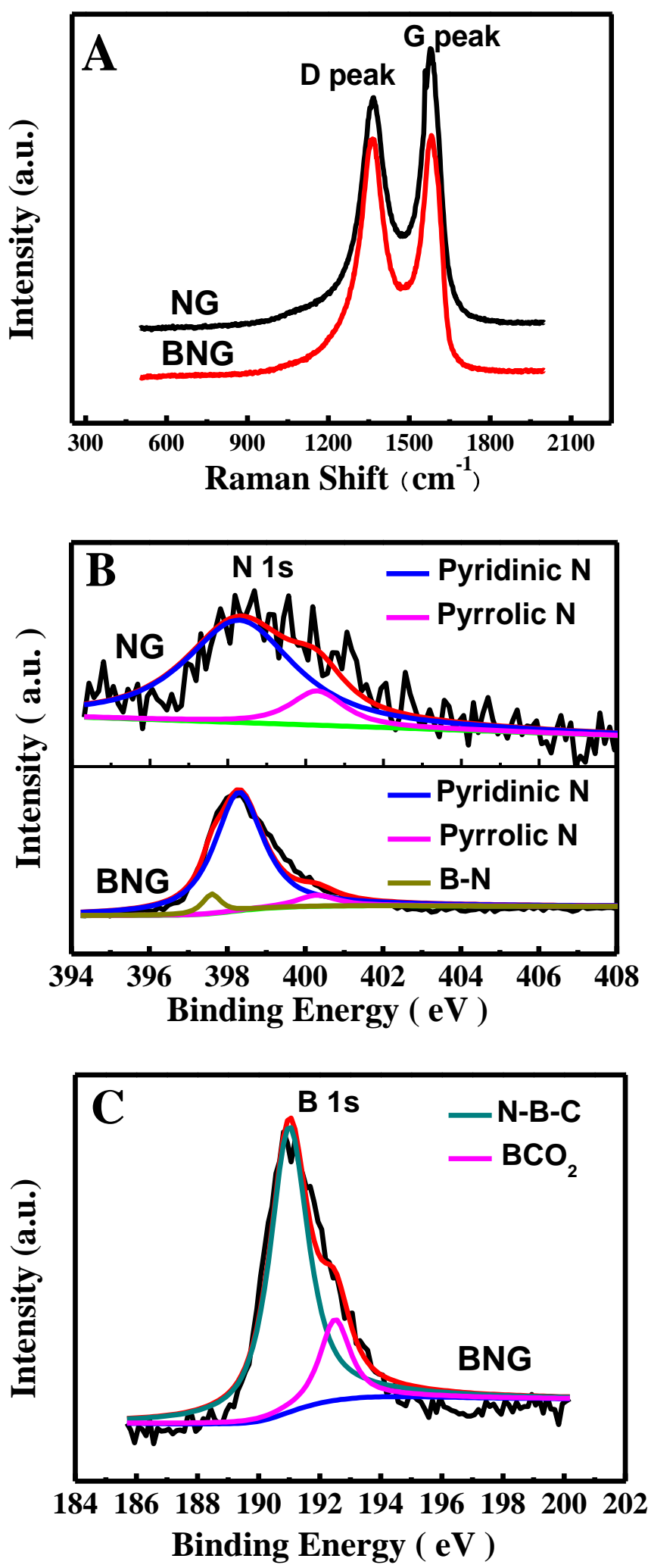

Fig. 2 . 

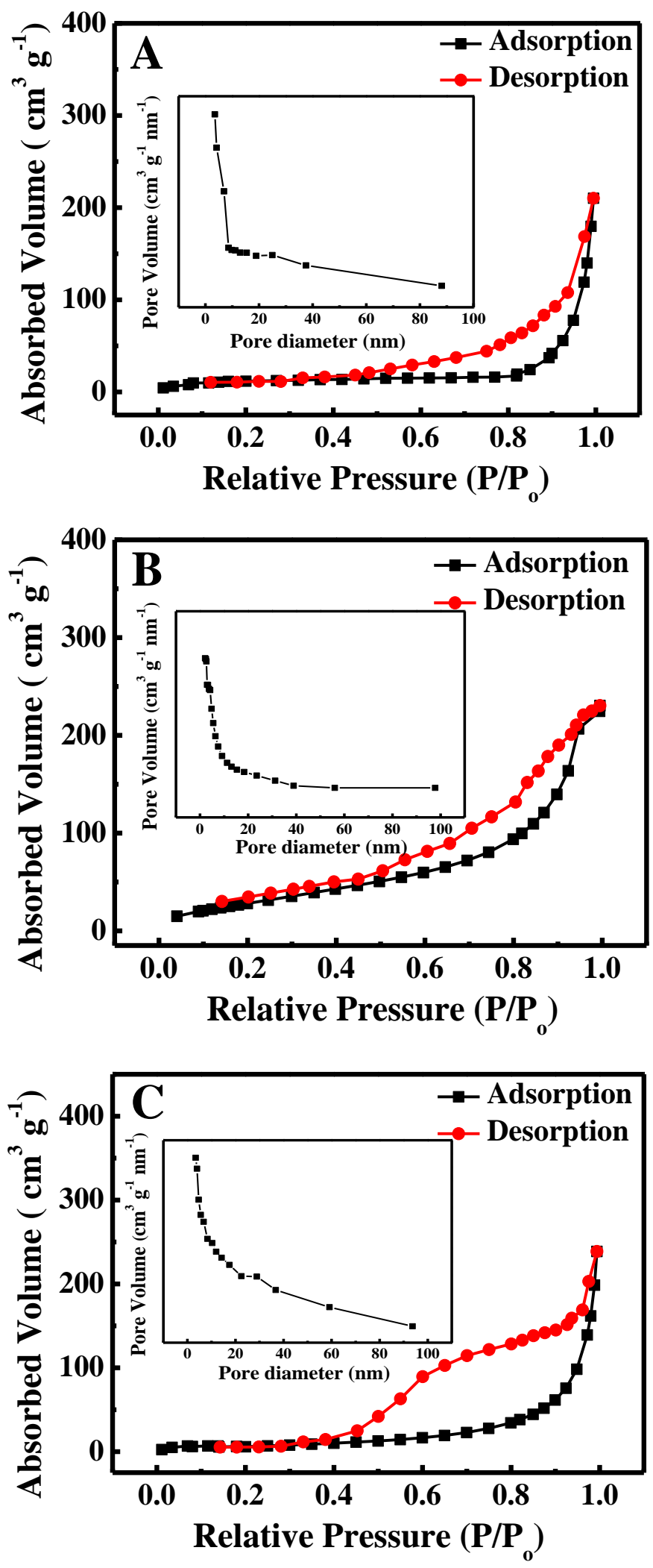

Fig. 3. 

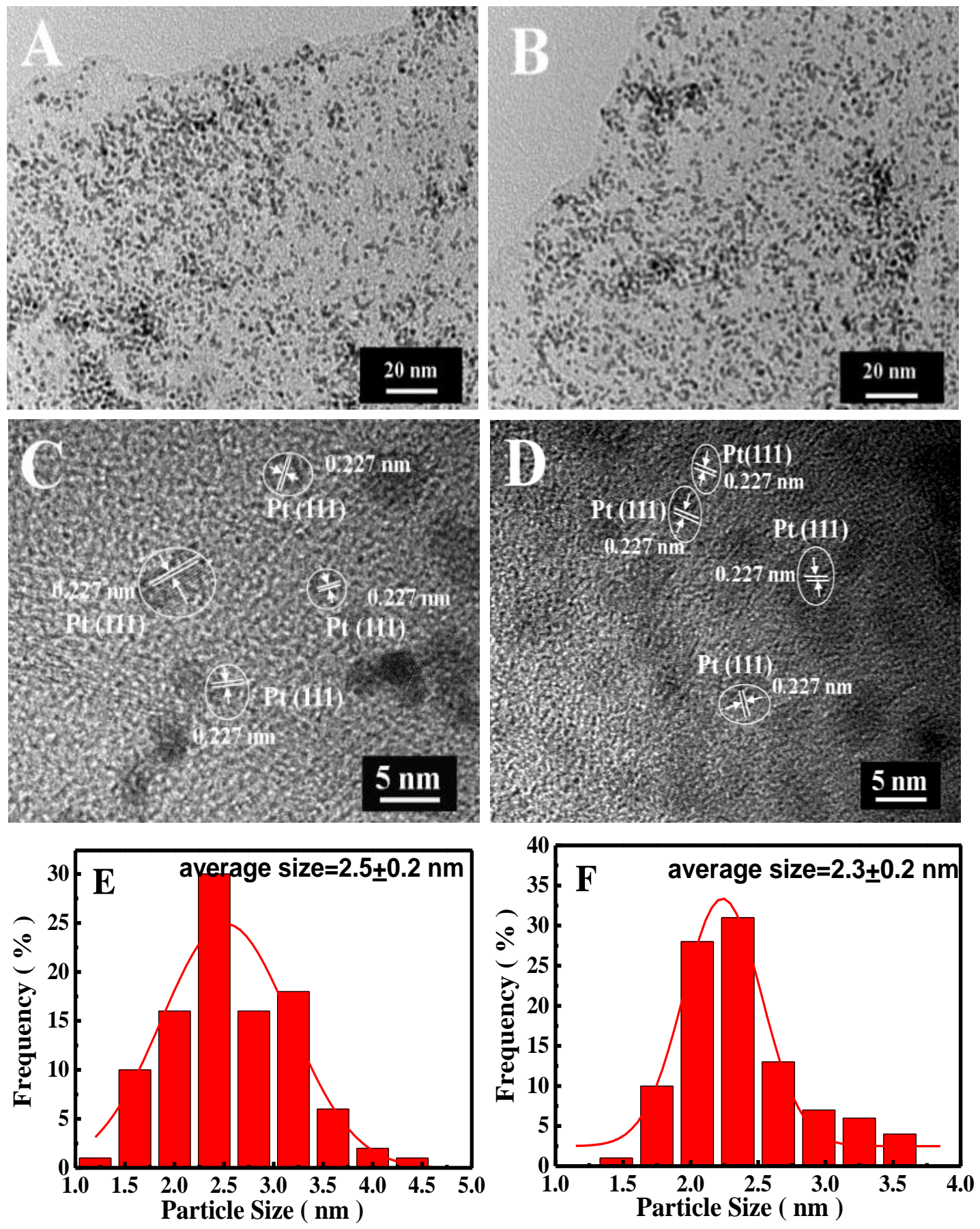

Fig.4. 

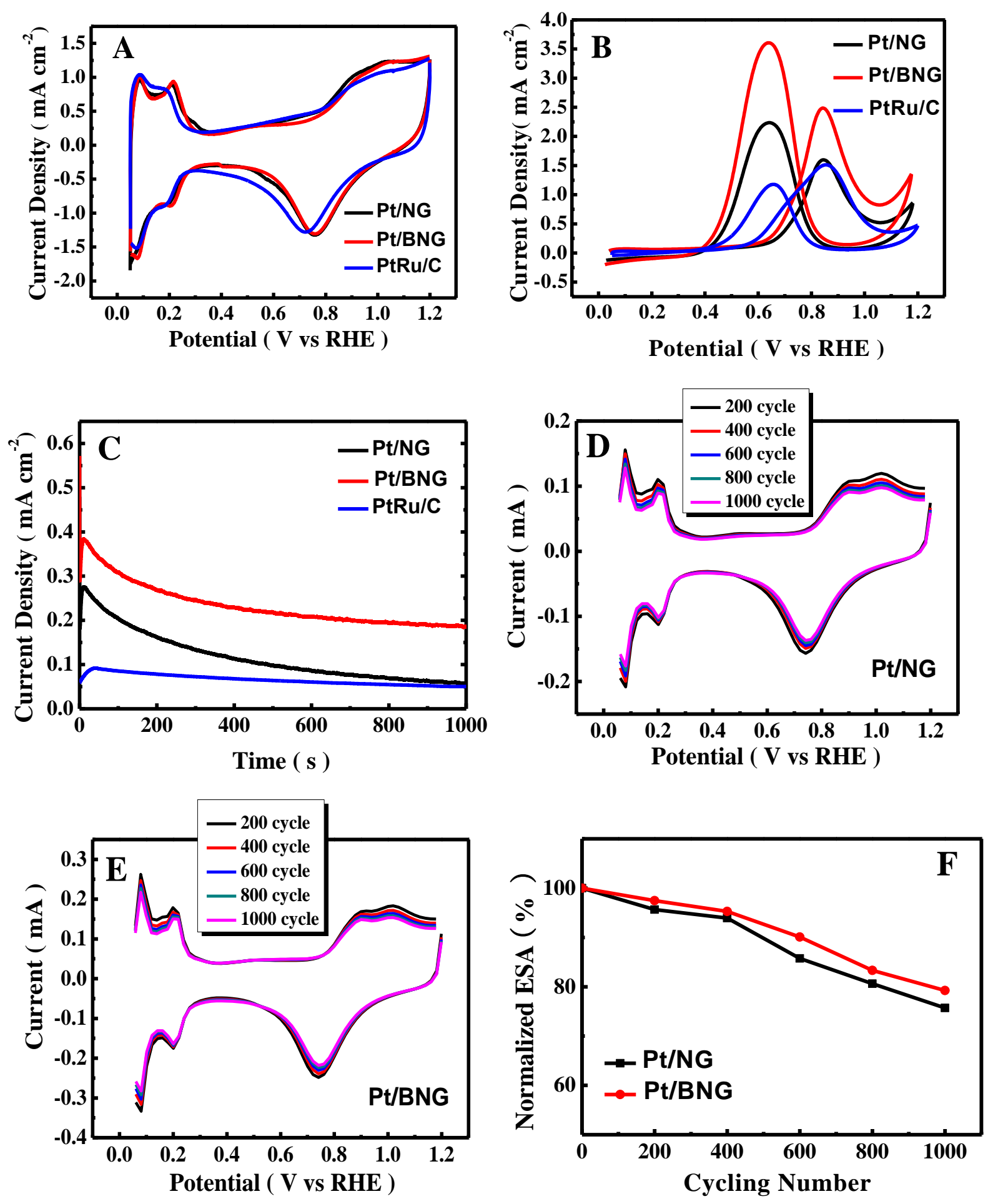

Fig. 5. 

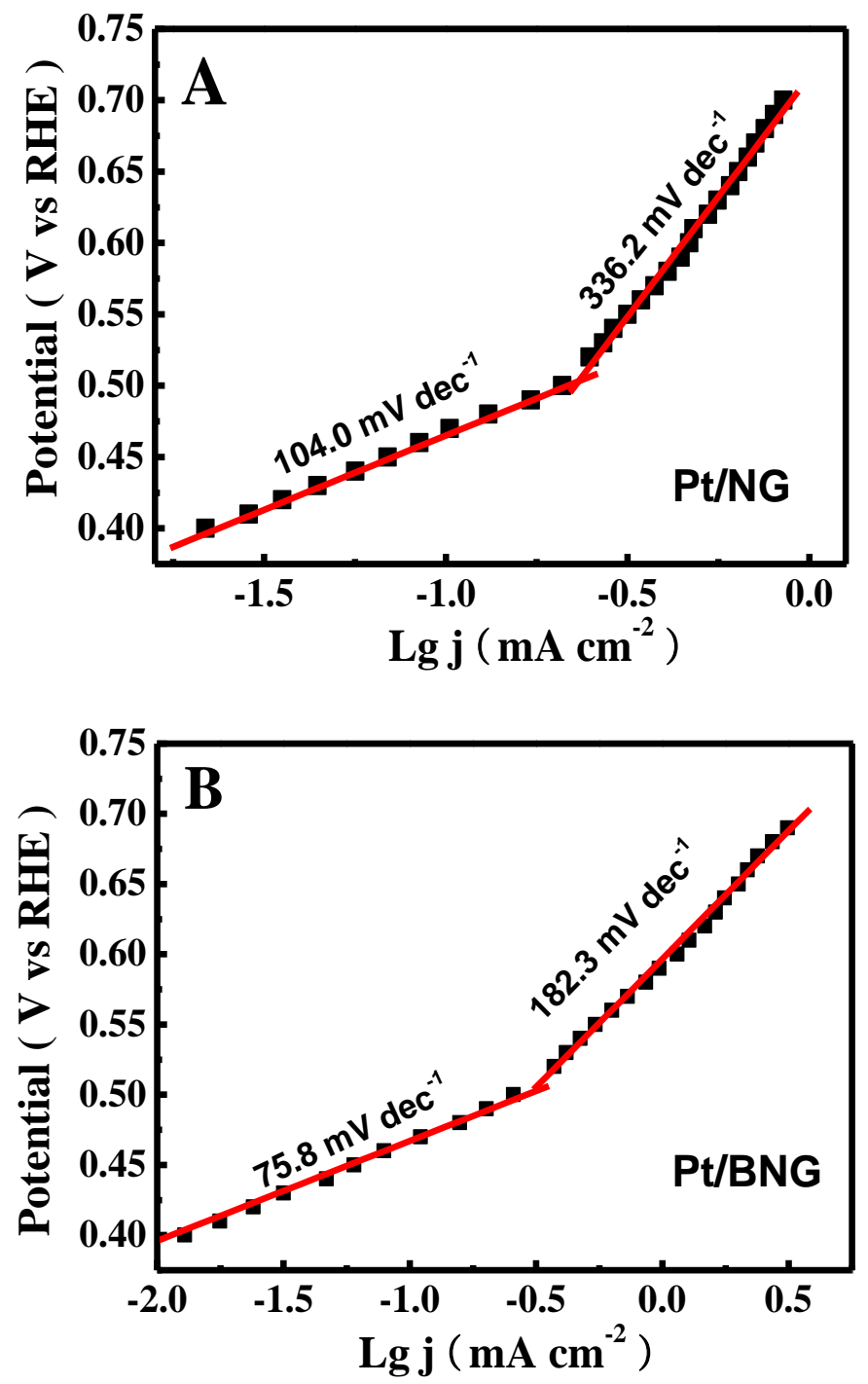

Fig. 6. 

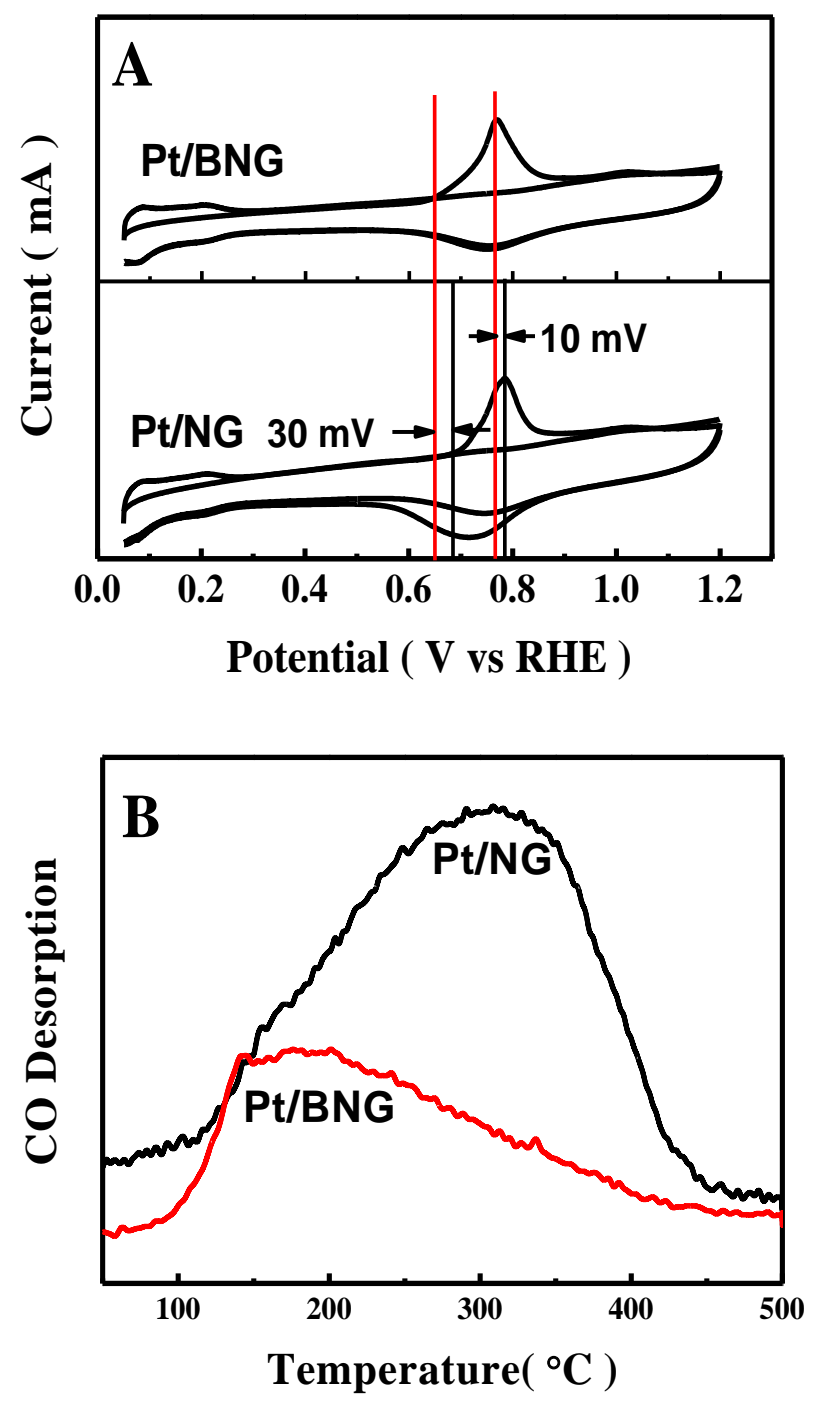

Fig. 7. 

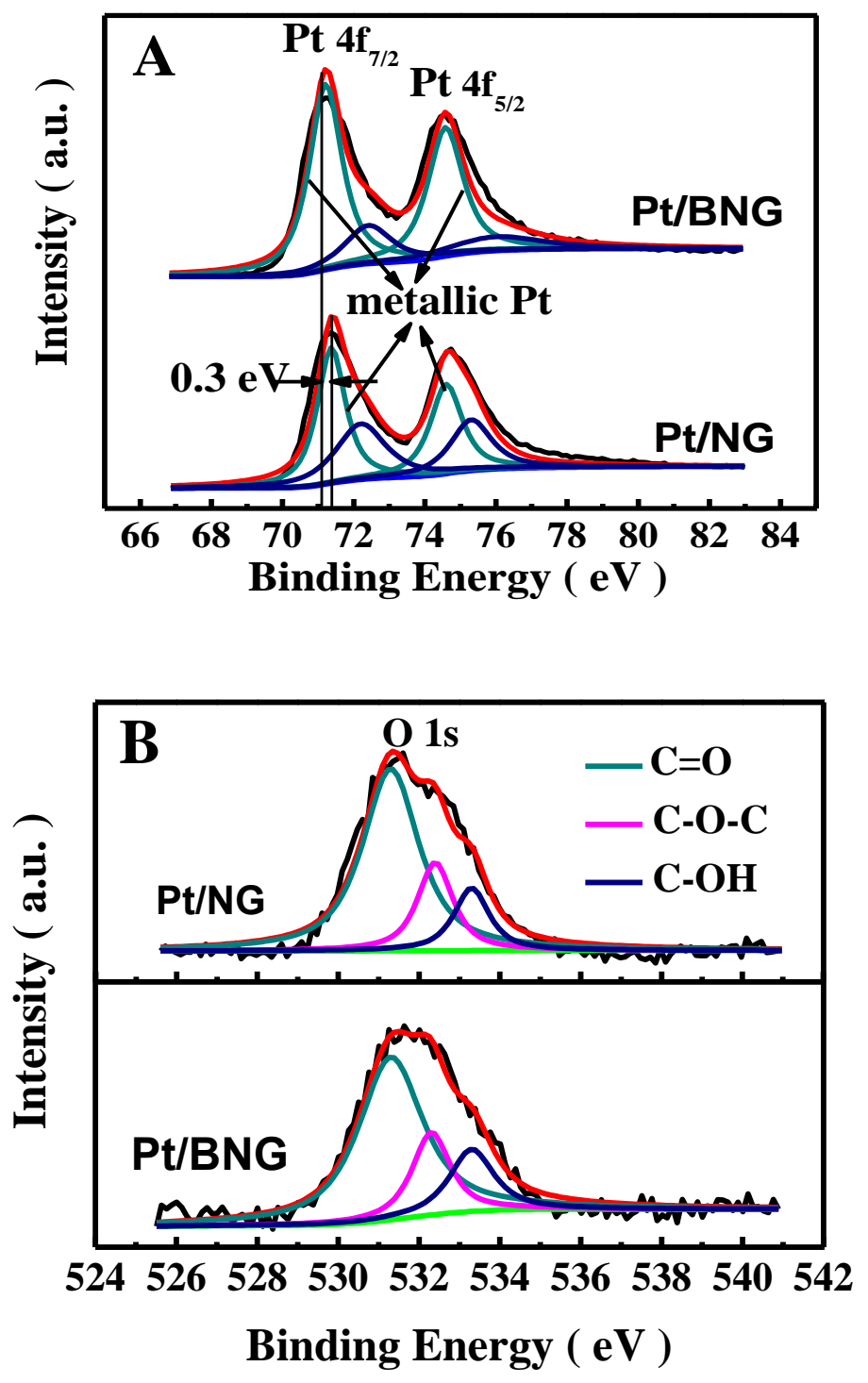

Fig. 8. 